Final Reports including

Annual Reports FY 2002 through 2004 of

Award \#DE-FC36-01G011092;

"Photoelectrochemical Hydrogen Production Using new Combinatorial Chemistry Derived Materials"

Dr. Eric McFarland 


\section{II.D.3 Photoelectrochemical Hydrogen Production Using New Combinatorial Chemistry Derived Materials}

Eric W. McFarland (Primary Contact), Sung Hyeon Baeck, Kyoung-Shin Choi, Anna Ivanovskaya, Thomas F. Jaramillo

Department of Chemical Engineering

University of California, Santa Barbara, CA 93106-5080

(805) 893-4343,fax: (805) 893-4732,e-mail: mcfar@engineering.ucsb.edu

DOE Technology Development Manager: Roxanne Danz

(202) 586-7260, fax: (202) 586-4753, e-mail: Roxanne.Danz@ee.doe.gov

Main Subcontractor: University of California, Santa Barbara, CA

\section{Objectives}

- Design and construct a versatile automated system and methodologies for automated electrochemical synthesis of combinatorial libraries of mixed metal oxides

- Define electrosynthetic routes amenable to the automated electrochemical deposition system for synthesizing for doped and mixed metal

- Develop an automated high-throughput photoelectrochemical screening system

- Create and screen libraries of materials

- Complete the development of a chemo-optical detection system based on optical sensing of the reduction of tungsten oxide as a high-throughput screening system for monitoring hydrogen production

- Begin exploratory synthesis and screening of new metal-oxide systems and begin to examine composition-structure-function relationships

- Design and synthesize libraries of potential patterned metal oxides using diverse types of structure directing agents under a variety of deposition conditions

\section{Approach}

- Create synthesis and screening systems for rapid automated combinatorial synthesis of materials suitable for photoelectrochemical hydrogen production

- Develop chemical synthesis routes amenable to automated high-throughput experimentation

- Utilize the automated synthesis systems to create libraries of potential hydrogen photocatalysts

- Rapidly screen libraries for potential materials with high photoelectrocatalytic activity

- Synthesize in conventional manner selected materials for detailed analysis

\section{Accomplishments}

- Designed and built several prototype systems for electrosynthetic deposition of metal oxides, including both parallel and automated serial systems

- Developed direct cathodic routes to oxides of several metals including tungsten (W), nickel (Ni), niobium $(\mathrm{Nb})$, titanium $(\mathrm{Ti}), \mathrm{Fe}$, copper $(\mathrm{Cu})$, colbalt $(\mathrm{Co})$, molybdenum $(\mathrm{Mo})$, and zinc $(\mathrm{Zn})$ by stabilization with several ligand types, and preliminary studies with libraries which have shown general trends 
- Completed our chemo-optical high throughput screening system and demonstrated the first thin film results with zinc oxide $(\mathrm{ZnO})$

- Preliminary work on electrosynthesis of mesoporous tungsten trioxide $\left(\mathrm{WO}_{3}\right)$ and titanium dioxide $\left(\mathrm{TiO}_{2}\right)$ films from a peroxo-stabilized electrolyte using ionic surfactants has at last shown definitive evidence of highly structured materials (July 2002)

- From libraries of pulsed electrodeposited platinum $(\mathrm{Pt})$ doped $\mathrm{WO}_{3}$, whereby a new means of creating nanoparticles has been developed. The nanoparticles show high activity for methanol oxidation without the poisoning problems of $\mathrm{Pt}$

\section{Future Directions}

- Explore the composition-function relationships of dopants in $\mathrm{ZnO}$ hosts

- Investigate metal oxide libraries for electrocatalytic hydrogen production and expand our highthroughput screening to include relative electrocatalytic overpotential as a routine screen

- Develop a high-throughput optical screening system to measure the effective bandgap of metal oxides in libraries

- Synthesize and screen model libraries optically for bandgap as a primary screen and create secondary libraries of compositions

- Investigate library designs for synthesis of semiconductor heterostructures utilizing two-photon absorption processes

- Continue and expand investigations of nanoporous materials with emphasis on the $\mathrm{ZnO}, \mathrm{WO}_{3}$ and $\mathrm{TiO}_{2}$ hosts.

\section{$\underline{\text { Introduction }}$}

The overall project objective is the development and application of combinatorial methods to discover an efficient, practical, and economically sensible material for photoelectrochemical production of hydrogen from water and sunlight. We will introduce a shift in the research paradigm from the present method of conventional serial chemical research to a combinatorial approach featuring a systematic and deliberate high-speed exploration of the composition-structure-property relationship of new metal-oxide based solid-state materials to discover new and useful energy producing materials as well as better understand the fundamental mechanisms and composition-structure functional relationships of these materials.

\section{Approach}

Our studies have focused on the development of automated chemical synthesis and screening systems, then on the preparation and analysis of diverse photoelectrochemical libraries of metal-oxides with semiconducting and other properties suitable for photoelectrocatalysis. Diversity has included: 1) variations in composition (by variable doping, electrochemical synthesis conditions, and surface redox catalysts) and 2) variations in structure (by deliberate and diverse ionic and non-ionic templating agents, synthesis conditions, and doping). The libraries are screened directly for hydrogen production using a two-dimensional chemo-optical sensor array.

\section{$\underline{\text { Results }}$}

$\underline{\text { Specific Aim } 1}$

Automated electrochemical synthesis routes are used to create libraries of mixed metal oxides, and we have designed and constructed the necessary apparatus and developed the detailed methodology to do so. Figure 1 schematically illustrates how our synthesis systems operate.

Combinatorial methods only make sense when very large numbers of different materials are made and screened quickly. Compositional diversity across a library is obtained by varying the 


\section{Rapid Serial Synthesis}

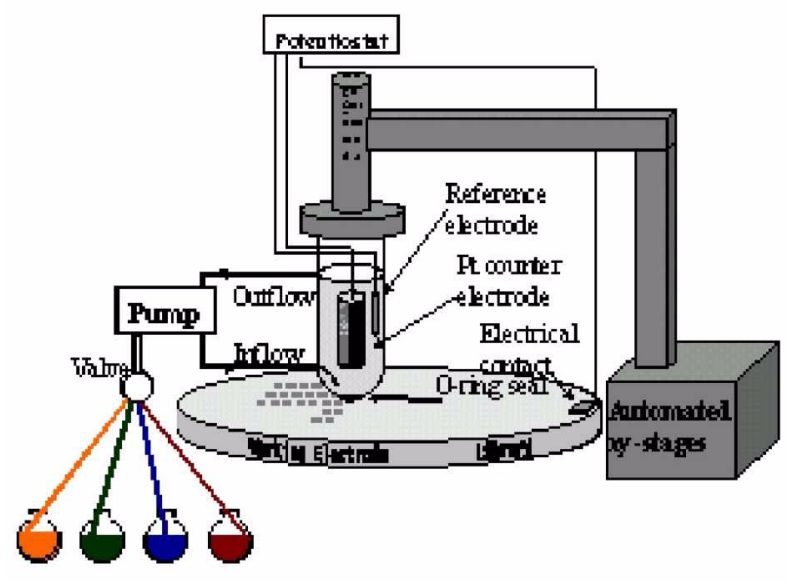

\section{Parallel Synthesis}

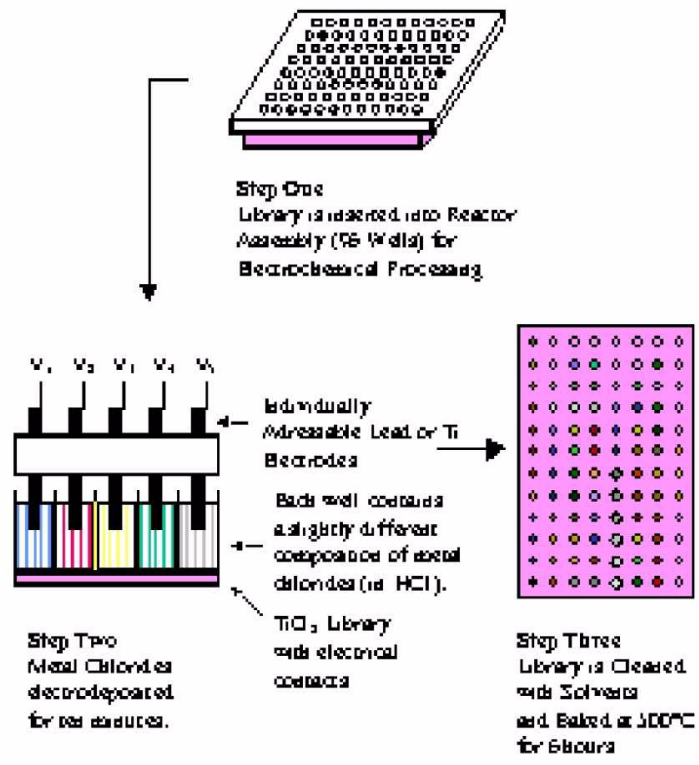

Figure 1. Schematic illustration of combinatorial synthesis by electrochemicaldeposition. The parallel approach is faster, but the rapid serial methodoffers greater control for each deposition.

electrochemical deposition conditions of time, voltage, current, surfactant additives and electrolyte. In the parallel system, the substrate (which is a common working electrode) has individual electrochemical cells isolated from each other by virtue of a perforated polypropylene block that is sealed to the substrate with an array of o-rings. This provides for different synthesis conditions at each library position; each cell constitutes an individual two-electrode system and is filled with a compositionally unique electrolyte. Clearly, synthesis speed is the advantage in a parallel scheme since all depositions occur simultaneously. In the rapid serial system, a complete three-electrode probe is scanned over the surface of the library substrate by an automated, computer-controlled set of $x-y-z$ stages. The probe contains an o-ring at the bottom which forms a seal at the substrate. Electrolyte of choice flows into the cell by a computer-controlled pump, and a highly controlled deposition is conducted at each location by a potentiostat/ galvanostat. Several material systems have exhibited extraordinary sensitivity to deposition voltage.

Specific Aim 2

We have developed new electrochemical synthesis routes and extended existing ones to create routes amenable to our automated synthesis system for the generation of mixed metal oxides.

A number of metal hydroxides have been deposited by cathodic reduction. Metal oxides $\left(\mathrm{WO}_{3}, \mathrm{MoO} 3, \mathrm{TiO}_{2}, \mathrm{ZnO}, \mathrm{Fe}_{2} \mathrm{O}_{3}, \mathrm{Co}_{3} \mathrm{O}_{4} \ldots\right)$ can be produced from the metal hydroxide by thermal annealing. In some cases, metal (Ni, $\mathrm{Zn}, \mathrm{Mn}$...) can be deposited by cathodic reduction and, after thermal annealing or electroanodization, a metal oxide can be obtained. We have also used electrochemical anodization for the synthesis of $\mathrm{Al}_{2} \mathrm{O}_{3}$ to roughen the surface and create a porous base material [13]. Our approach has been to stabilize the metal cations with ligands to allow for direct metal oxide deposition and the co-deposition of dopant cations. Several ligands we have used include hydrogen peroxide, citric acid, lactic acid, and acetic acid. $\mathrm{WO}_{3}, \mathrm{TiO}_{2}, \mathrm{Nb}_{2} \mathrm{O}_{5}$, and $\mathrm{MoO}_{3}$ have been cathodically deposited from metalperoxo solution. We have found that mixed metal oxides, such as $\mathrm{WO}_{3}-\mathrm{MoO}_{3}$, and $\mathrm{WO}_{3}-\mathrm{TiO}_{2}$ can be synthesized by mixing metal peroxo electrolytes. Pt or Ru doped tungsten oxide has been directly deposited under cathodic conditions in the presence of hydrogen peroxide, and diversity has been achieved by changing the concentration of the dopants in the electrolyte solution or by varying deposition potential. We have also stabilized the 


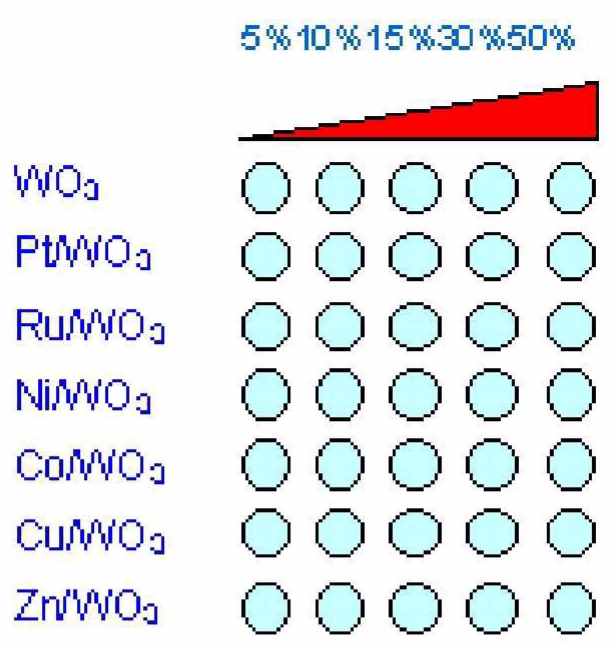

(a)

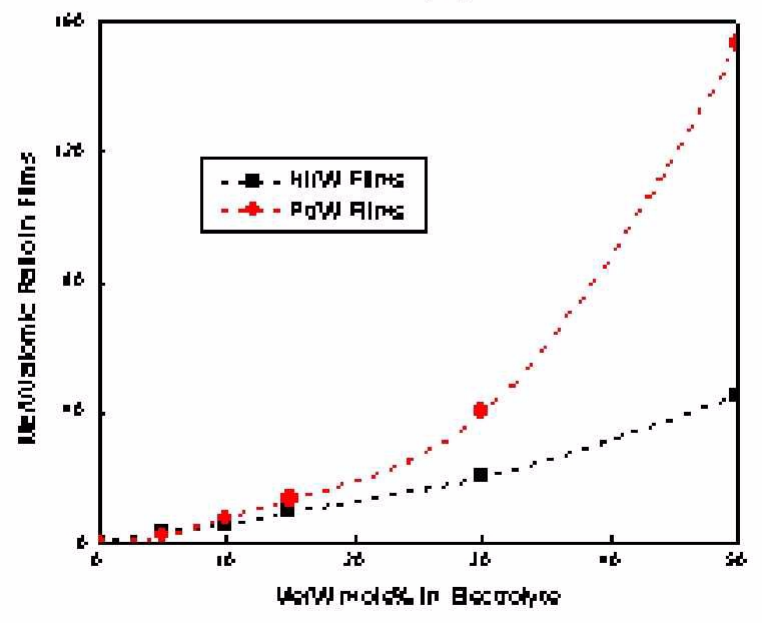

(b)

Figure. 2. Metal-doped $\mathrm{WO}_{3}$ binary library. (a) Library design: variation indoping density is achieved by varying dopant concentration in theelectrolyte. (b) Relationship between dopant concentration in thedeposited film versus dopant concentration in the electrolyte.

metal cations in basic media using a complexing agent such as citric and lactic acid.

\section{Specific Aim 3}

We have developed two major systems for automated high-throughput photoelectrochemical screening designed to measure electrochemical and photoelectrochemical responses of combinatorially prepared photocatalyst libraries. The system in its electrochemical screening configuration allows for measuring cyclic voltammograms (I-V curves) and Mott-Schottky plots, which reveal flatband potential and sample dopant concentrations. The system is modular in nature - easy to set up for the experiment of interest by connecting the appropriate programmable source/measure devices: potentiostat, digital multimeter, data acquisition board, impedance analyzer and lock-in amplifier. This configuration allows for varying electrolytes for different samples by filling the wells of a perforated polypropylene block with a programmable pipette.

\section{$\underline{\text { Specific Aim } 4}$}

We created a pair of libraries of $\mathrm{WO}_{3}$ doped with different transition metals (at a variety of doping densities) with the aim of improving upon the photocatalytic activity of pure $\mathrm{WO}_{3}$. The first library design is shown in Figure 2(a). The library incorporates $\mathrm{Pt}, \mathrm{Ru}, \mathrm{Ni}, \mathrm{Co}, \mathrm{Cu}$, and $\mathrm{Zn}$ as dopants within polycrystalline $\mathrm{WO}_{3}$. The materials were each co-deposited with $\mathrm{WO}_{3}$ electrochemically from a mixture of $50 \mathrm{mM}$ metal chloride solution and a $\mathrm{W}$ peroxo solution. Altering the metal-chloride concentrations in the electrolyte, from $0 \%$ to $50 \%$ allowed for variation of doping concentrations within the deposited films. Figure 2(b) shows the relationship between doping density in the deposited film versus the concentration in the electrolyte for $\mathrm{Pt}$ and $\mathrm{Ni}$ as determined by Electron Dispersive X-Ray (EDX). Figure 3(a) illustrates the zero-bias photocurrent for the library members, and Figure 3(b) shows a cyclic voltammogram taken of the pure $\mathrm{WO}_{3}$ film. We expect several photocurrent trends from this library. First of all, Ni has been shown to be an excellent absorber of visible light when doped into large band-gap oxide hosts, such as $\mathrm{WO}_{3}$, so we expect an increase in photocurrent from that row. Similarly, we would expect better photocurrent from $\mathrm{Pt}$ and $\mathrm{Ru}$ dopants, since $\mathrm{Pt}$ is an excellent reduction catalyst and $\mathrm{RuO}_{2}$ is a well-known oxidation catalyst. Figure 3(a) shows that, indeed, Ni doping increased photocurrent significantly compared to pure $\mathrm{WO}_{3}$, with a maximum photocurrent achieved for $10 \% \mathrm{Ni}$. $\mathrm{Pt}$ and $\mathrm{Ru}$ dopants show a different trend.

Seemingly, a greater doping concentration of either element decreases the photoactivity of $\mathrm{WO}_{3}$. 


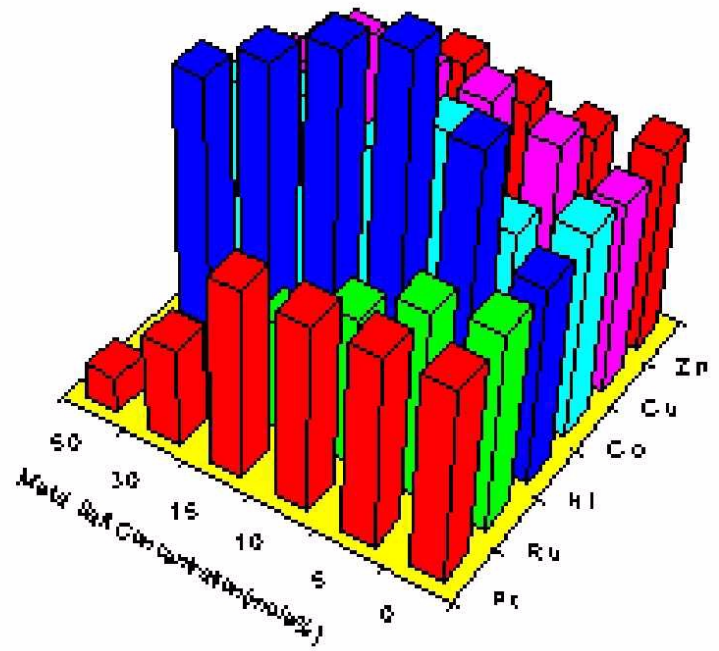

(a)

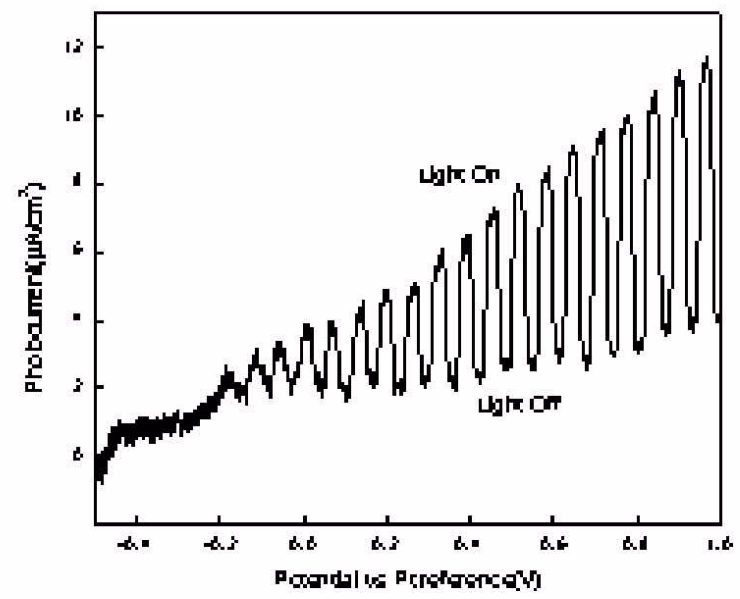

(b)

Figure 3. High-throughput photocurrent screening of the $\mathrm{WO}_{3}$ library at zero bias.(a) Photocurrent trends in the library. (b) Cyclic voltammogram of pure $\mathrm{WO}_{3}\left(0.2 \mathrm{~cm}^{2}\right)$ under chopped illumination from a $150 \mathrm{~W}$ Xe lamp $\left(2.3 \mathrm{~mW} / \mathrm{cm}^{2}\right)$.

\section{$\underline{\text { Specific Aim } 5}$}

We have engineered a high-throughput screening system for monitoring $\mathrm{H}_{2}$ production based on a chemo-optical $\mathrm{H}_{2}$ sensor [14-16]. This colorimetric sensor utilizes a $\mathrm{Pd} / \mathrm{WO}_{3}$ bilayer, whereby molecular $\mathrm{H}_{2}$ dissociates on the $\mathrm{Pd}$ surface and diffuses as atomic hydrogen to reduce $\mathrm{WO}_{3}$ to a tungsten bronze, $\mathrm{H}_{\mathrm{y}} \mathrm{WO}_{3-\mathrm{x}}$. The reduced tungsten oxide is
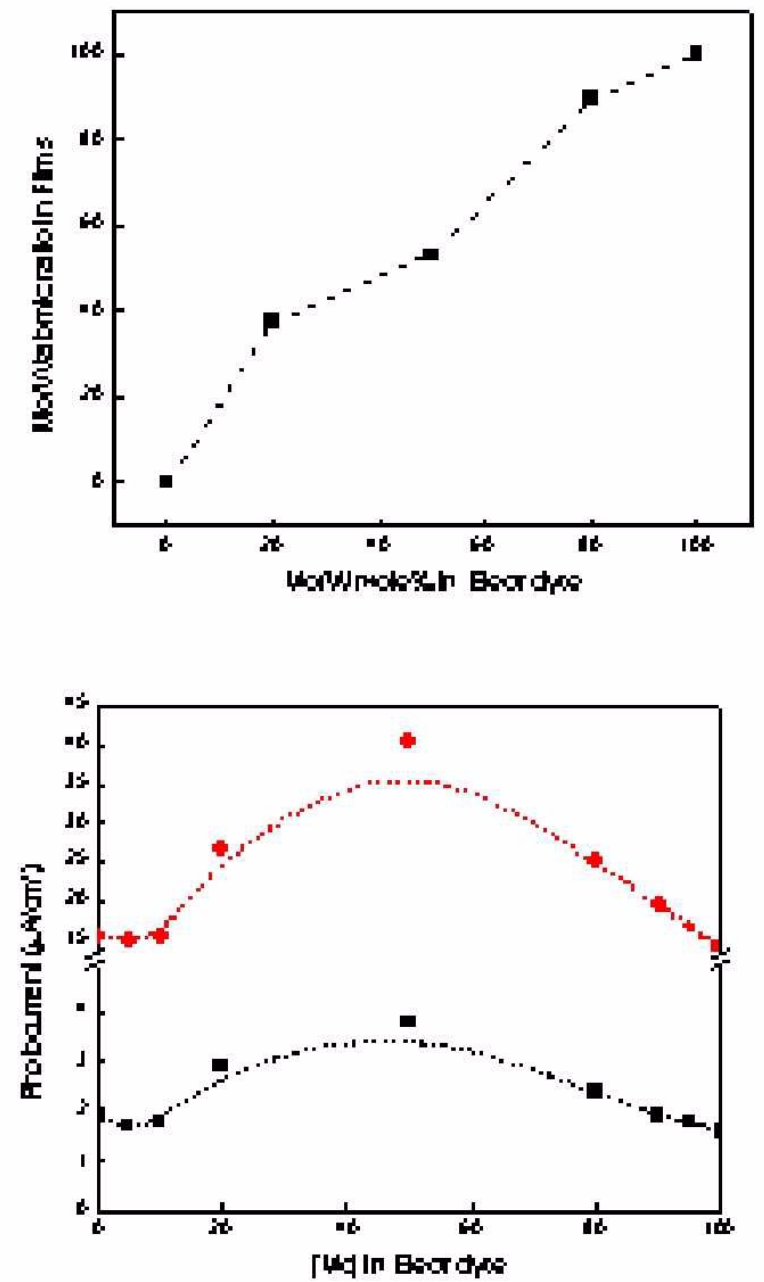

Figure 4. (a) EDS measured atomic ratio of Mo to $\mathrm{W}$ in films as a function of Mo concentration in electrolyte. (b) Photocurrents in $0.1 \mathrm{M}$ sodium acetatesolution at zero bias(=)and $1 \mathrm{~V}$ bias $(<)$ for $\mathrm{WO}_{3}-\mathrm{MoO}_{3}$ mixed oxides as a function of Mo concentration in electrolyte.

photometrically distinct from $\mathrm{WO}_{3}$ due to a decreased index of refraction. The reduction is reversible and the sensor can be regenerated in $\mathrm{O}_{2}$. Details are presented in our published papers.

\section{$\underline{\text { Specific Aim } 6}$}

A library consisting of a 45 -member ( $5 \times 9$ array) $\mathrm{WO}_{3}-\mathrm{MoO}_{3}$ mixed binary oxide library, with diversity achieved by variations in deposition voltage and Mo concentration in the electrolyte was synthesized. The concentration of Mo was varied 
from 0 to $100 \mathrm{~mol} \%$ and all films were deposited for 10 minutes. After deposition, the library was calcined at $450^{\circ} \mathrm{C}$ for 4 hours in air.

The film compositions were determined by EDX for fifth row (prepared from 50\% W- 50\% Mo mixture) and fourth column (electrodeposited at -1.0 V). As expected, with increasing concentration of molybdenum in solution, the atomic fraction of molybdenum in the film increased (Figure 4(a)). However, the atomic ratio was independent of deposition voltage (-0.2 - $1.5 \mathrm{~V}$, not shown). A trend in photoresponse as a function of molybdenum concentration in electrolyte was clearly observed. Figure 4(b) shows photocurrent at 0 and $+1 \mathrm{~V}$ bias for the $\mathrm{WO}_{3}-\mathrm{MoO}_{3}$ mixed oxide. The photoresponse increased and reached a maximum when $50 \%$ Mo and $50 \% \mathrm{~W}$ concentration in electrolyte was used, and then decreased as concentration of Mo in electrolyte increased. In the cases where $\mathrm{MoO}_{3}$ concentration was below $10 \%$ or above $90 \%$, there is no enhancement of photoactivity compared to either pure $\mathrm{WO}_{3}$ or pure $\mathrm{MoO}_{3}$. Interestingly, in the range of $20 \sim 80 \% \mathrm{MoO}_{3}$, an increase of photoactivity was observed.

Nano-particulate tungsten oxide films were also synthesized by pulsed electrodeposition in libraries. Particle sizes between $45 \sim 330 \mathrm{~nm}$ were achieved by varying pulse duration from $5 \mathrm{~ms}$ to $500 \mathrm{~ms}$. Films prepared by continuous electrodeposition had an average particle size of approximately $375 \mathrm{~nm}$. As the pulse time decreased, particle size decreased as well. For a $5 \mathrm{msec}$ pulsed deposition, the average particle size was approximately $45 \mathrm{~nm}$. We checked the particle size with respect to deposition time (30 sec to $30 \mathrm{~min}$, that is 3,000 to 180,000 pulses) and found that particle size was independent of total number of pulses; the total number of pulses seemed to affect only film thickness and not the final particle size.

We discovered that metal oxides $\left(\mathrm{WO}_{3}, \mathrm{MoO}_{3}\right.$, $\mathrm{TiO}_{2}, \mathrm{Nb}_{2} \mathrm{O}_{5}$ ) can be synthesized from peroxostabilized solution onto $\mathrm{Cu}$ foil by electroless deposition. The deposition rate was found to be strongly dependent on temperature, electrolyte concentration, and deposition time. As-synthesized films were amorphous and showed weak p-type photocurrent due to the formation of $\mathrm{Cu}_{2} \mathrm{O}$ on the surface of $\mathrm{Cu}$ foil. After calcination at $450^{\circ} \mathrm{C}$, metal oxide films were found to be crystalline. A 27member ( 3 x 9 array) $\mathrm{WO}_{3}-\mathrm{MoO}_{3}$ mixed oxide library was prepared by electroless deposition on $\mathrm{Cu}$ foil, with diversity achieved by variations in deposition time and Mo concentration in electrolyte.

\section{$\underline{\text { Specific Aim } 7}$}

In addition to our effort of finding better performance photocatalysts by tuning the composition of the films, we have been developing a general method for the production of high surface area nanostructured films by utilizing electrochemically driven self-assembly of surfactants at solid-liquid interfaces. We combined potentialcontrolled surface assembly with an electrodeposition process to fabricate nanostructured films. We have successfully electrodeposited mesoporous platinum and zinc oxide films by controlling deposition potentials and electrolyte compositions. The nanostructures of these films have been confirmed by transmission electron microscopy (TEM). The hexagonal structure of the $\mathrm{Pt}$ films, with the pores perpendicular to the substrate and the lamellar structure of $\mathrm{ZnO}$, with the normal direction of the layers parallel to the substrate, are expected to allow facile access of the guest molecules and analytes to the pores and interlayers. The electrocatalytic properties of mesoporous $\mathrm{Pt}$ films, towards methanol oxidation were measured in order to confirm the increased effective surface areas and to evaluate a potentially important application of these films (i.e. direct methanol fuel cell applications).

\section{$\underline{\text { Conclusions }}$}

Our work during the first 9 months of this project has focused on the development of combinatorial methods to rapidly synthesize and high-throughput screen mixed metal oxides, and on using these systems to begin to investigate new materials for photocatalytic hydrogen production. We have designed and constructed much of the combinatorial infrastructure (automated parallel and rapid serial synthesis and screening systems), and we have developed synthesis routes (based on electrochemistry) amenable to our combinatorial instruments. Rapid synthesis and functional 
screening of mixed metal oxides of $\mathrm{W}, \mathrm{Cu}, \mathrm{Ti}$, and $\mathrm{Fe}$ hosts has been demonstrated, and new

electrosynthetic routes to W-Mo-oxide and nanoporous $\mathrm{WO}_{3}$ have been developed. Recent data from $\mathrm{W}_{\mathrm{x}}(\mathrm{Mo}, \mathrm{Ni}, \mathrm{Pt})_{\mathrm{y}} \mathrm{O}_{\mathrm{z}}, \mathrm{Cu}_{\mathrm{x}}\left(\mathrm{Zn}_{\mathrm{y}} \mathrm{Ni}_{\mathrm{y}}\right) \mathrm{O}_{\mathrm{z}}$ and $\mathrm{Fe}_{\mathrm{x}}(\mathrm{Ti})_{\mathrm{y}} \mathrm{O}_{\mathrm{z}}$ show (reserved) promise as improved materials.

\section{References}

1. Gaffron, H and Rubin, J., J. Gen. Physiol., 26, 219 (1942).

2. Fujishima, A. and Honda, K, Nature, 238, 37 (1972).

3. Herriman, A. and West, M. A., editors, "Photogeneration of Hydrogen", Royal Institution Symposium, Academic Press (1982).

4. Domen, K., Kondo, J. N., Hara, M., and Takata, T., Bull. Chem. Soc. Jpn., 73, 1307 (2000).

5. Gratzel, M. A., "Energy Resources through Photochemistry and Catalysis", Academic Press, New York (1983).

6. Hanak, J. J., J. Mater. Sci., 5, 964 (1970).

7. Hanak, J. J., Gittleman, J. I., Pellicane, J. P., and Bozowski, S., Phys. Lett., 30(3), 210 (1969).

8. Danielson, E., Golden, J. H., McFarland, E. W., Reaves, C. M., Weinberg, W. H., and Wu, X. D., Nature, 389, 944 (1997).

9. Danielson, E., Devenney, M., Giaquinta, D. M., Golden, J. H., Haushalter, R. C., McFarland, 10. E. W., Poojary, D. M., Reaves, C. M., Weinberg, W. H., and Wu, X. D., Science, 279, 837 (1998).

10. Therese G. H. A. and Kamath, P. V., Chem. Mater., 12, 1195 (2000).

11. Meulenkamp, E. A., J. Electrochem. Soc., 144, 1664 (1997).

12. Hutchins, M. G., Kamel, N. A., El-Kardy, W., Ramadan, A. A., and Abdel-Hady, K., Phys. Stat. Sol. A , 175, 991(1999).
13. Brandli, C., Jaramillo, T. F., Ivanovskaya, A., and McFarland, E. W., Electrochimica Acta, 47, 553 (2001).

14. Ito, K. and Ohgami, T., Appl. Phys. Lett., 60, 938 (1992).

15. Ito, K. and Kubo, T., Proceedings of the 4th Sensor Symposium, Tokyo, 153 (1984).

16. Tamura, H., Hashimoto, Y., and Ito, K., Solid State Phenom., 51-52, 429 (1996).

17. Shen, P., Chi, N., and Chan. K. Y., J. Mater. Chem., 1, 697 (2000).

18. Burgess, I., Jeffrey, C. A., Cai, X., Szymanski, G., Galus, Z., and Lipkowski, J., Langmuir, 15, 2607 (1999).

\section{FY 2002 Publications/Presentations}

1. S.H. Baeck, T.F. Jaramillo, C. Brandli, and E. McFarland, "Combinatorial Electrochemical Synthesis and Characterization of Tungsten-based Mixed Metal Oxides", J. Combi. Chemistry, (accepted and in press 2002).

2. S.H. Baeck, T.F. Jaramillo, G.D. Stucky, and E. McFarland, "Controlled Electrodeposition of Nanoparticulate Tungsten Oxide", Nano Letters, (accepted and in press 2002).

3. S.H. Baeck and E.W. McFarland, "Combinatorial Electrochemical Synthesis and Characterization of Tungsten-Molybdenum Mixed Oxides", Korean.J.Chem.Eng., (accepted and in Press 2002).

4. S.H. Baeck, T.F. Jaramillo, and E. McFarland, "Influence of Composition and Morphology on Photo and Electrocatalytic Activity of Electrodeposited $\mathrm{Pt} / \mathrm{WO}_{3}$ ", 224th National ACS Conference Proceedings, Boston, MA (2002).

5. Invited Seminar October 2001 "Combinatorial Methods of New Materials Discovery For Photocatalytic Hydrogen Production: A Long Way to a Million Million Watts", Department of Nuclear Engineering, MIT. 
6. Invited Talk November 2001 "Combinatorial

Electrosynthesis and Photoelectrocatalytic Screening of New Materials for Hydrogen

Photosynthesis", AICHE Annual Meeting, Reno, Nevada. 


\title{
Photoelectrochemical Hydrogen Production Using New Combinatorial Chemistry Derived Materials
}

\author{
Eric W. McFarland (Primary Contact), Sung Hyeon Baeck, Thomas F. Jaramillo, Alan Kleiman- \\ Shwarsctein \\ Department of Chemical Engineering \\ University of California, Santa Barbara, CA 9310-5080 \\ Phone: (805) 893-4343; Fax: (805) 893-4732; E-mail: mcfar@engr.ucsb.edu
}

DOE Technology Development Manager: Roxanne Danz

Phone: (202) 586-7260; Fax: (202) 586-9811; E-mail: Roxanne.Danz@ee.doe.gov

\section{Objectives}

- Continue synthesis and screening of libraries designed in year 1 and follow promising (lead) materials as they are identified.

- Explore the composition-function relationship of dopants in $\mathrm{ZnO}$ hosts.

- Investigate metal oxide libraries for electrocatalytic hydrogen production and expand our highthroughput screening to include relative electrocatalytic overpotential as a routine screen.

- Develop a high-throughput optical screening system to measure the effective bandgap of metal oxides in libraries.

- Synthesize and screen model libraries optically for bandgap as a primary screen; create secondary libraries of compositions with solar spectrum adsorption and subsequently screen the derivate libraries for appropriate redox/flatband levels and finally for $\mathrm{H}_{2}$ production.

- Investigate library design for synthesis of semiconductor heterostructures utilizing two-photon absorption processes.

- Continue to expand our investigation of nanoporous materials with emphasis on the $\mathrm{ZnO}, \mathrm{WO}_{3}$ and $\mathrm{TiO}_{2}$.

- Participate as a member of the USA Annex-14 Expert Group in the International Energy Agency's (IEA's) Hydrogen Implementing Agreement on photoelectrolytic hydrogen production.

\section{Technical Barriers}

This project addresses the following technical barriers from the Hydrogen Production section of the Hydrogen, Fuel Cells and Infrastructure Technologies Program Multi-Year R,D\&D Plan:

- M. Material Durability

- N. Materials and System Engineering

- O. Photoelectrochemical Efficiency

\section{Approach}

- Using new and existing high-throughput synthesis and screening technology, create and screen suitable new mixed metal oxide materials for electrochemical/photoelectrochemical hydrogen production.

- Improve and expand the chemical synthesis routes developed for automated high-throughput experimentation.

- Utilize the automated synthesis systems to create libraries of potential hydrogen electrocatalysts/ photocatalysts. 
- Rapidly screen libraries for potential materials with electrocatalytic and/or photoelectrocatalytic activity.

- Synthesize, using conventional routes, selected materials identified in libraries for detailed structural and electronic analysis.

\section{Accomplishments}

- Designed and fabricated combinatorial chemistry systems for synthesis and screening of hydrogen production photocatalysts (Figures 1a, 1b).

- Demonstrated that compositional and preparative modifications of known metal oxide hosts may improve their photoelectrocatalytic properties (Figure 2).

- Achieved first electrochemical synthesis of ordered nanoporous metal oxides (Figure 5).

- Discovered nanoparticulate $\mathrm{Pt} / \mathrm{WO}_{3}$, which is photoactive and resistant to $\mathrm{CO}$ poisoning.

- Developed methods for and demonstrated controlled electrosynthesis of high-activity Au nanocluster catalysts.

- Identified $\mathrm{H}$ intercalation as a critical component of poisoning resistance of metal oxide electrocatalysts.

\section{Future Directions}

- Expand the exploration of new materials with the parallel synthesis and screening systems with particular emphasis on expanding the exploration of the composition-function relationships of quartenary $\mathrm{ZnO}$ systems.

- Develop an automated spray pyrolysis methodology and system as a means of high-throughput synthesis and demonstrate the system for dopants in iron-based hosts.

- Expand the search for improved photoelectrochemical performance from nanoporous/nanoparticulate morphologies of known hosts.

- Using calibrated standards, obtain quantitative values of the efficiencies of the materials under investigation in terms of electrons per photon and power efficiency.

- Begin definition and design of photoelectrochemical reactor systems which can incorporate the new materials, and perform preliminary process design calculations on a large-scale hydrogen plant to establish cost estimate models.

\section{Introduction}

The overall project objective is to utilize combinatorial material science to expedite the discovery of an efficient, practical, and economically sensible material for the photoelectrochemical production of hydrogen from water and sunlight. This represents a shift in the research paradigm from conventional serial chemical research to a combinatorial approach that features systematic and high-speed exploration of new metal-oxide based solid-state materials. By investigating large arrays of diverse materials, we are working to improve the understanding of the fundamental mechanisms and composition-structure-property relationships within these systems while discovering new and useful energy-producing photocatalysts.

\section{$\underline{\text { Approach }}$}

As we have developed automated chemical synthesis and screening systems during the first two years of the program, in the second year we have focused on the preparation and analysis of diverse metal-oxide libraries with semiconducting and other properties suitable for photoelectrocatalysis. Diversity has included (1) variations in composition (by variable doping, electrochemical synthesis 
conditions, and surface redox catalysts) and (2) variations in structure (by deliberate and diverse ionic and non-ionic templating agents, synthesis conditions, and doping). The libraries are primarily screened by photoelectrochemical methods, including zero-bias photocurrent and cyclic photovoltammetry.

\section{$\underline{\text { Results }}$}

Task 1. We created tungsten-molybdenum mixed oxide libraries $\left(\mathrm{W}_{1-\mathrm{x}} \mathrm{Mo}_{\mathrm{x}} \mathrm{O}_{3}\right)$ using a parallel synthesis method. The film compositions were

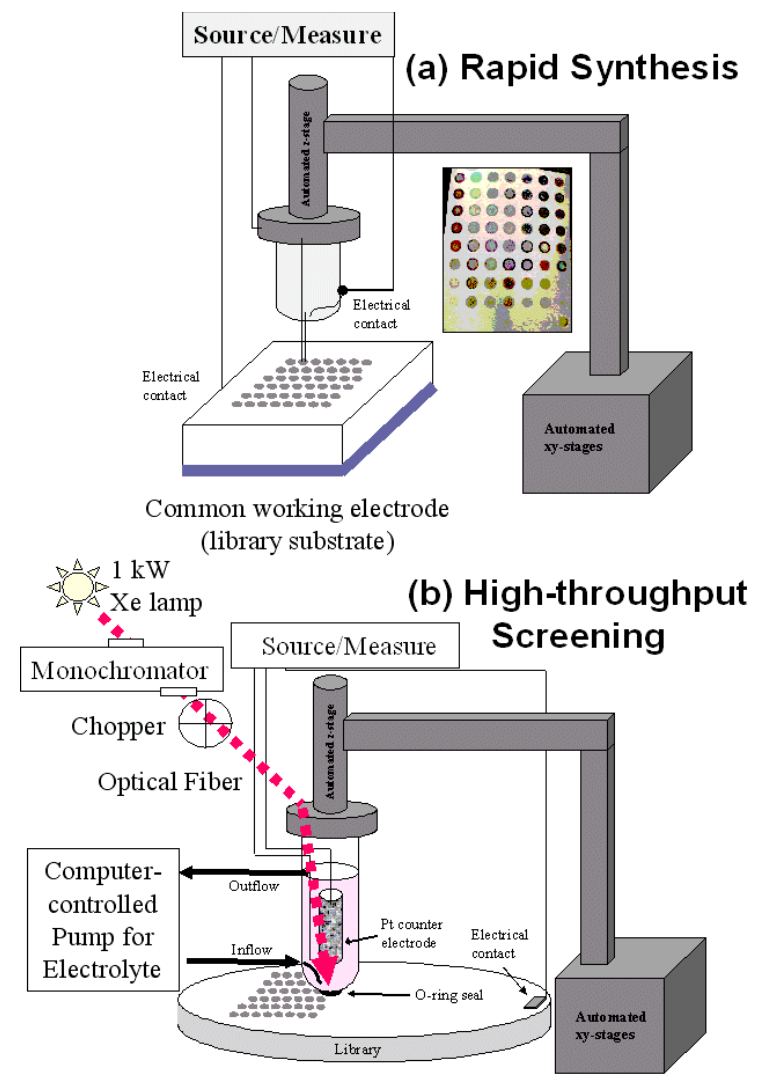

Figure 1. Automated Electrochemical Synthesis and Screening: (a) Rapid synthesis - a perforated polypropylene block with 63 independent orings is sealed upon a substrate, allowing for 63 distinct electrolyte compositions. A probe with reference and counter electrodes are automatically dipped into each bath, and a potentiostat conducts electrodeposition of each sample. (b) High-throughput screening - a scanning photoelectrochemical cell traverses a library, illuminating each sample with a chopped light source, and photocurrent is measured. readily controlled by varying the ratios of the two metals in the electrolyte. By X-ray diffraction patterns and Raman spectroscopy, atomically-mixed metal oxides were confirmed to exist rather than simply mixed phases of pure tungsten oxide and pure molybdenum oxide (Figure 2). Zero-bias photocurrents of the mixed oxides were strongly dependent on the film composition. The maximum photoresponse was observed with $\mathrm{W}_{0.5} \mathrm{Mo}_{0.5} \mathrm{O}_{3}$, and photoactivity decreased as film composition approached either pure oxide. The photoresponse of the $\mathrm{W}_{0.5} \mathrm{Mo}_{0.5} \mathrm{O}_{3}$ mixed oxide film, $18.5 \mu \mathrm{A} / \mathrm{cm}^{2}$, was $50.4 \%$ higher than that of the pure tungsten oxide film. Cation intercalations were carried out for
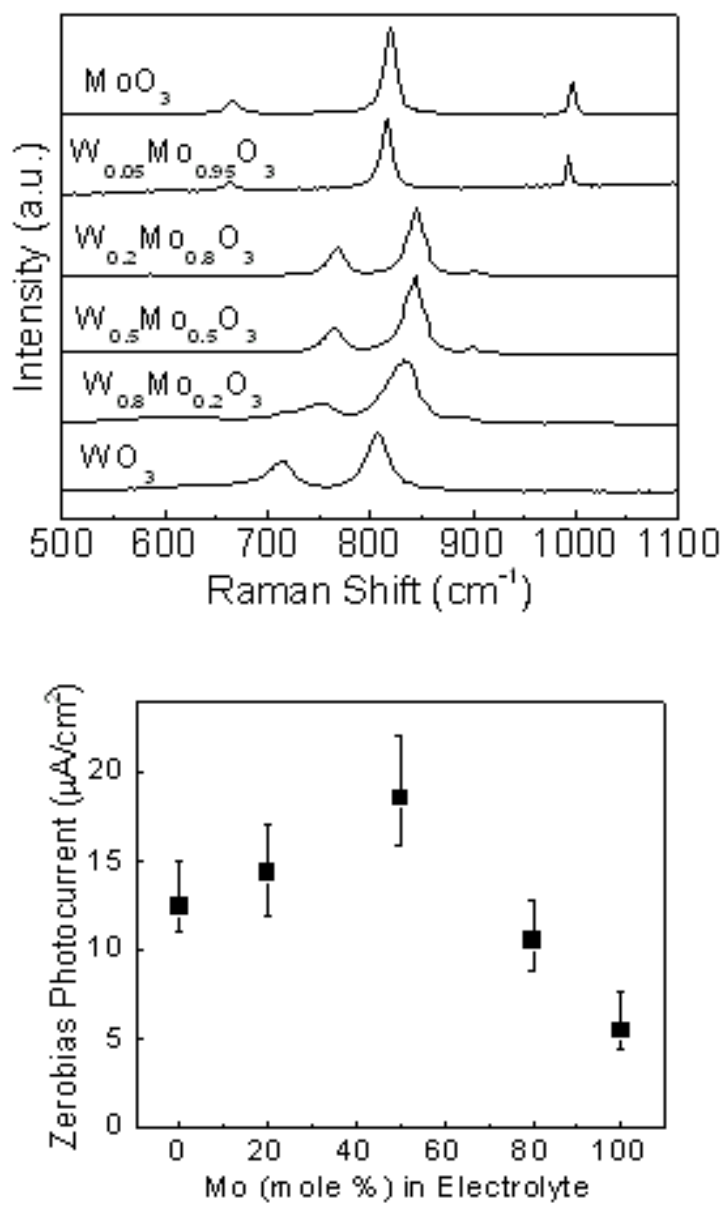

Figure 2. (top) Raman spectroscopy of tungstenmolybdenum mixed oxides with respect to film compositions and (bottom) Zero-bias photocurrent of tungsten-molybdenum mixed metal oxide films. All samples were n-type semiconductors. Illumination was provided by a 150-W Xe lamp. 
the tungsten-molybdenum mixed oxide library using $\mathrm{H}^{+}, \mathrm{Li}^{+}, \mathrm{Na}^{+}$, and $\mathrm{K}^{+}$. Interestingly, as the ratio of tungsten to molybdenum approaches unity, electrochromic properties improve. Compared to either pure tungsten oxide or pure molybdenum oxide, the mixed oxides show considerably enhanced intercalation properties, with the $\mathrm{W}_{0.5} \mathrm{Mo}_{0.5} \mathrm{O}_{3}$ film exhibiting the highest intercalation properties of all. Metal oxide libraries were also successfully synthesized by electroless deposition on copper substrates from metal peroxo electrolytes $\left(\mathrm{WO}_{3}\right.$, $\mathrm{MoO}_{3}, \mathrm{ZrO}_{2}, \mathrm{Nb}_{2} \mathrm{O}_{5}$ ). The reducing electrons were provided by the copper substrate as it was oxidized to $\mathrm{CuO}$.

Task 2. Several hundred samples of different $\mathrm{ZnO}$-based materials have been synthesized and screened for zero-bias photocurrent. All materials were binary systems consisting of $\mathrm{ZnO}$ and a single other element - typically a transition metal - and a range of dopant concentrations was explored for each element. The aim of the dopant is to improve upon the photocatalytic activity of $\mathrm{ZnO}$, particularly under visible illumination, and to increase the stability of the material. Table 1 has been constructed to qualitatively indicate the impact of the dopants on the material properties vs. pure $\mathrm{ZnO}$ ("very poor", "poor", "average", "good", and "excellent"). Cobalt showed the greatest improvements in terms of visible light photocurrent, and the photoactivity of cerium samples remained high for several minutes, as opposed to pure $\mathrm{ZnO}$, whose photocurrent decayed to $15 \%$ of its initial value after the same amount of time. Iron, nickel, ruthenium, and manganese also showed improvements to $\mathrm{ZnO}$. After having explored 24 different binary $\mathrm{ZnO}$ systems, of different concentrations, we are looking forward to focusing on the best materials to begin our investigation of ternary and quaternary libraries.

Task 3. Diverse compositions of cobalt-iron-nickel oxide materials supported on 304 stainless steel have been synthesized by combinatorial spray pyrolysis. These samples have been studied for water oxidation electrocatalysis by tafel slopes and exchange current in basic electrolytes (KOH 20\% w/w). Different precursor solutions were used to create compositional differences. The best electrocatalysts found to date in this study were synthesized with iron or nickel at $10-20 \%$ of the cobalt concentration in solution. Ternary libraries will be explored in the near future.

Tasks $4 \&$ 5. We are currently completing our infrastructure for the automated measurement of bandgap of combinatorial libraries. The system is shown schematically in Figure 3. In this design, an integrating sphere is affixed to our $x-y-z$ combinatorial stages. In a fully automated fashion, the integrating sphere steps down upon each sample independently, and each sample is illuminated by a 1$\mathrm{kW}$ Xe lamp (ThermoOriel). An optical fiber carries the diffuse reflectance of the sample to an Ocean Optics S2000 detector, which measures the spectra and allows for bandgap calculation. This combinatorial method for bandgap measurement will be the first screening conducted on libraries.

Task 6. Heterostructures of $\mathrm{Cu}_{2} \mathrm{O} / \mathrm{TiO}_{2}$ have been synthesized and screened for photocatalytic activity.

Table 1. Qualitative impact (excellent, good, average, poor, very poor) of 24 different elements when co-deposited with $\mathrm{ZnO}$ as compared to pure $\mathrm{ZnO}$.

\begin{tabular}{|c|c|c|c|}
\hline $\begin{array}{c}\text { Co-deposited } \\
\text { species with Zno }\end{array}$ & $\begin{array}{c}\text { Visible } \\
\text { Photocurrent }\end{array}$ & $\begin{array}{c}\text { UV-Vis } \\
\text { Photocurrent }\end{array}$ & Stability \\
\hline $\mathrm{Ag}$ & Poor & Poor & Average \\
\hline $\mathrm{Al}$ & Good & Average & Good \\
\hline $\mathrm{Au}$ & Poor & Poor & Average \\
\hline $\mathrm{Ce}$ & Average & Average & Excellent \\
\hline $\mathrm{Cd}$ & Poor & Poor & Average \\
\hline Co & Excellent & Poor & Good \\
\hline $\mathrm{Cr}$ & Poor & Poor & Average \\
\hline $\mathrm{Cu}$ & Poor & Poor & Average \\
\hline $\mathrm{Eu}$ & Poor & Poor & Average \\
\hline $\mathrm{Fe}$ & Good & Good & Average \\
\hline $\mathrm{Mn}$ & Average & Average & Good \\
\hline Mo & Poor & Poor & Poor \\
\hline $\mathrm{Ni}$ & Excellent & Excellent & Average \\
\hline $\mathrm{Nb}$ & Poor & Average & Good \\
\hline $\mathrm{Pd}$ & Very Poor & Very Poor & N/A \\
\hline $\mathrm{Pt}$ & Poor & Poor & Poor \\
\hline $\mathrm{Rh}$ & Poor & Poor & Aveage \\
\hline $\mathrm{Ru}$ & Excellent & Excellent & Average \\
\hline $\mathrm{Sb}$ & Poor & Poor & Average \\
\hline Sn & Average & Average & Good \\
\hline $\mathrm{Ti}$ & Very Poor & Very Poor & N/A \\
\hline $\mathrm{V}$ & Poor & Poor & Average \\
\hline W & $\mathrm{N} / \mathrm{A}$ & N/A & $\mathrm{N} / \mathrm{A}$ \\
\hline $\mathrm{Zr}$ & Average & Average & Good \\
\hline
\end{tabular}


The $\mathrm{Cu}_{2} \mathrm{O} / \mathrm{TiO}_{2}$ heterojunction scheme can be viewed in Figure 4. $\mathrm{Cu}_{2} \mathrm{O}$ is a photocatalyst that benefits from a small bandgap $(2.0 \mathrm{eV})$, which allows for excellent solar absorption. It is limited, however, by photocorrosion which degrades the material rapidly. $\mathrm{TiO}_{2}$, on the other hand, is a robust photocatalyst that is stable for long periods of time (ca. thousands of hours); however, it is limited by poor visible photon absorption (bandgap $3.0 \mathrm{eV}$ ). By creating a heterojuction of $\mathrm{Cu}_{2} \mathrm{O}$ covered with $\mathrm{TiO}_{2}$, a photocatalytic system (which operates as a photocathode) results which absorbs more visible light than pure $\mathrm{Cu}_{2} \mathrm{O}$ and is as stable as pure $\mathrm{TiO}_{2}$.

Task 7. We have been developing a general method for the production of high surface area nanostructured films by utilizing electrochemicallydriven self-assembly of surfactants. We have successfully electrodeposited mesoporous $\mathrm{WO}_{3}$, $\mathrm{TiO}_{2}$ by controlling deposition conditions (Figure 5). Mesoporous tungsten oxide films with lamellar structure were successfully synthesized by electrodeposition using sodium dodecylsulphate (SDS) as a templating agent. Nanophases can be varied by changing the deposition potential, which directly affects the surface charge densities of the electrode and, therefore, the surface assembly patterns of the inorganic-surfactant aggregates. Compared to nonporous tungsten oxide prepared with isopropanol, lamellar phase mesoporous tungsten oxide showed higher photocatalytic activity

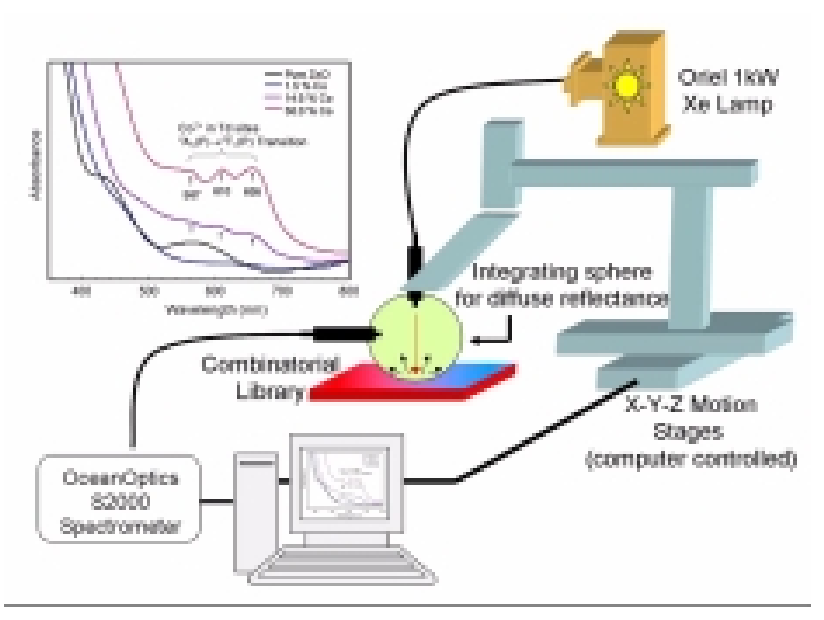

Figure 3. Schematic design of combinatorial measurement of diffuse reflectance for ultraviolet-vis spectroscopy and bandgap calculation. and greater current density for hydrogen intercalation. Functional improvements are most probably due to the larger surface area of mesoporous tungsten oxide and facilitated charge transport.

Task 8. We have actively contributed to the Annex 14 of the IEA, including attendance and participation in the expert meeting in Paris, France, April 27-28. Results were presented to the Annex working group from our laboratory, and we shared ideas concerning the future of international collaboration in the area of photoelectrochemical water splitting.
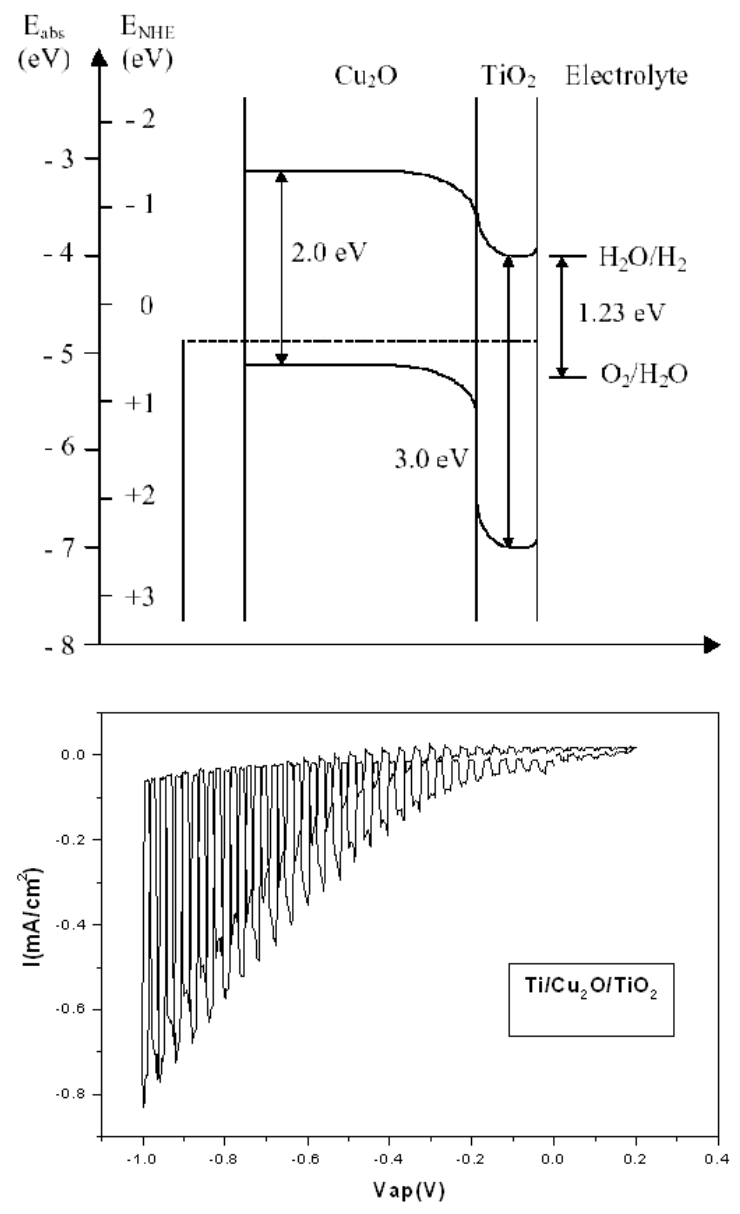

Figure 4. $\mathrm{Cu}_{2} \mathrm{O} / \mathrm{TiO}_{2}$ Heterojunction on Ti Foil: (top) The $\mathrm{Cu}_{2} \mathrm{O}$ functions as a light absorber and the $\mathrm{TiO}_{2}$ overlayer protects against corrosion. The band diagram demonstrates why the device operates as a photocathode despite n-type $\mathrm{TiO}_{2}$ on the surface. (bottom) The device produces nearly $1 \mathrm{~mA} / \mathrm{cm}^{2}$ of photocurrent at $-1 \mathrm{~V}$ bias vs. $\mathrm{Ag} / \mathrm{AgCl}$ under 1 sun illumination. 


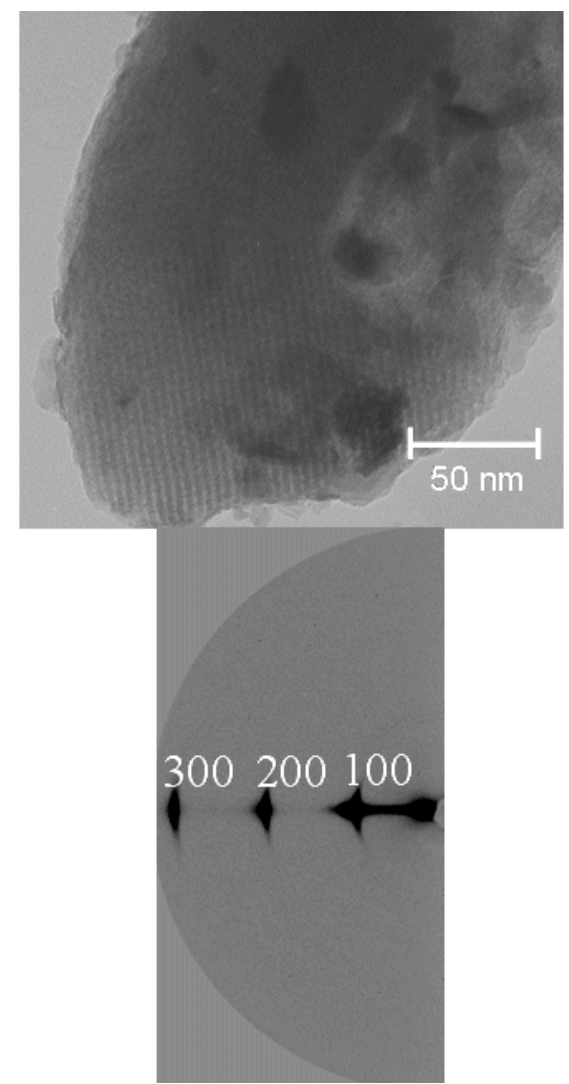

Figure 5. Nanoporous Metal Oxide Photocatalyts: (top) Transition electron microscopy images of tungsten oxide films deposited in the presence of SDS and (bottom) 2D-grazing incidence $x-$ ray diffraction pattern of lamellar tungsten oxide on indium tin oxide coated glass.

\section{$\underline{\text { Conclusions }}$}

As we complete the second year of the project in the fall of 2003, we will have developed combinatorial methods for high-throughput synthesis and screening of new mixed-metal oxides active for photoelectrochemical production of hydrogen. Mixed $\mathrm{WO}_{3}-\mathrm{MoO}_{3}$ has shown improvements over the pure oxide components, and binary $\mathrm{ZnO}: \mathrm{Me}(\mathrm{Me}$ $=\mathrm{Co}, \mathrm{Ni}, \mathrm{Fe}, \mathrm{Ru}, \mathrm{Ce}, \mathrm{Mn}$ ) have demonstrated improved photocatalytic performance compared to pure $\mathrm{ZnO}$. A new means of nanoporous metal oxide synthesis has been demonstrated and Pt and $\mathrm{Au}$ nanoparticles created electrochemically which show promise as new surface electrocatalysts.

\section{FY 2003 Publications/Presentations}

1. S.-H. Baeck, T. Jaramillo, G. Stucky, and E. McFarland, "Controlled Synthesis of Nanoparticulate Tungsten Oxide", Nano Letters, 2(8), 831-834(2002).

2. S.-H. Baeck, C. Brandly, T. Jaramillo, and E. McFarland, "Combinatorial Electrochemical Synthesis and Characterization of Tungsten based Mixed Metal Oxide", Journal of Combinatorial Chemistry, 4(6), 563-568 (2002).

3. S.-H. Baeck, T. Jaramillo, and E. McFarland, "Influence of Composition and Morphology on Photo and Electrocatalytic Activity of Electrodeposited Pt/ $\mathrm{WO}_{3}$ ", Abstracts of Papers of American Chemical Society, 224: 062-FUEL Part 1 (2002).

4. S.-H. Baeck and E. McFarland, "Combinatorial Electrochemical Synthesis and Characterization of Tungsten-Molybdenum Mixed Oxides," Korean Journal of Chemical Engineering, 19 (4), 593-596 (2002).

5. K.-S. Choi, H. Lichtenegger, G. Stucky, and E. McFarland, "Electrochemical Synthesis of Nanostructured ZnO Films Utilizing SelfAssembly of Surfactant Molecules at Solid-Liquid Interfaces", Journal of the American Chemical Society, 124(42), 12402-12403 (2002).

6. W. Siripala, A. Ivanovskaya, T. Jaramillo, S.-H. Baeck, and E. McFarland," $\mathrm{A} \mathrm{Cu}_{2} \mathrm{O} / \mathrm{TiO}_{2}$ Hetrojuction Thin Film Cathode for Photoelectrocatalysis", Solar Energy Materials \& Solar Cells, 77(3), 229-237 (2003).

7. T. Jaramillo, S.-H. Baeck, B.R. Cuenya, and E. McFarland, "Catalytic Activity of Supported Au Nanoparticles Deposited From Block Co-polymer Micelles", Journal of the American Chemical Society, 125(24), 7148-7149 (2003).

8. K.-S. Choi, E. McFarland, and G. Stucky, "Electrocatalytic Properties of Thin Mesoporous Platinum Films Synthesized Utilizing Potential- 
Controlled Surfactant Assembly", Advanced

Materials, Accepted and in Press (2003).

9. S.-H. Baeck, K.-S. Choi, T. Jaramillo, G. Stucky, and E. McFarland, "Enhancement of Photocatalytic and Electrochromic Properties of Electrochemically Fabricated Mesoporous $\mathrm{WO}_{3}$ Thin Films", Advanced Materials, Accepted and in Press (2003 August).

10.S.-H. Baeck, T. Jaramillo, G. Stucky, and E. McFarland, "Synthesis of Tungsten Oxide on Copper Surfaces by Electroless Deposition", Chemistry of Materials, Accepted and in Press (2003 August). 


\section{Photoelectrochemical Hydrogen Production Using New Combinatorial Chemistry Derived Materials (2003-2004)}

Eric W. McFarland (Primary Contact), Thomas F. Jaramillo, Sung-Hyeon Baeck, Alan Kleiman-Shwarsctein, Galen D. Stucky

Dept. of Chemical Engineering

University of California

Santa Barbara, CA 93106-5080

805-893-4343; 805-893-4731; mcfar@engineering.ucsb.edu

DOE Technology Development Manager: Roxanne Danz

202 586-7260 Roxanne.Danz@ee.doe.gov

\section{Objectives}

- Continue synthesis and screening of libraries designed in previous years and follow promising (lead) materials as they are identified.

- Explore the composition-function relationship of dopants in $\mathrm{ZnO}$ hosts.

- Investigate metal oxide libraries for electrocatalytic hydrogen production and expand our high-throughput screening to include electrocatalytic overpotential as a routine screen.

- Develop a high-throughput optical screening system to measure the effective bandgap of metal oxides in libraries.

- Synthesize and screen model libraries optically for bandgap as a primary screen; create secondary libraries of compositions with solar spectrum adsorption and subsequently screen the derivate libraries for appropriate redox/flatband levels and finally for $\mathrm{H}_{2}$ production.

- Continue to expand our investigations of nanoporous materials with the emphasis on $\mathrm{ZnO}, \mathrm{WO}_{3}$ and $\mathrm{TiO}_{2}$.

- Participate as a member of the USA Annex-14 Expert Group in the International Energy Agency's (IEA's) Hydrogen Implementing Agreement on photoelectrolytic hydrogen production.

\section{Technical Barriers}

This project addresses the following technical barriers from section 3.1 of the Hydrogen, Fuel Cells and Infrastructure Technologies Program Multi-Year Research, Development and Demonstration Plan (2003-2010):

- M. Material Durability

- N. Materials and System Engineering

- O. Photoelectrochemical Efficiency

\section{Approach}

- Systems Development

o Continuing synthesis \& high-throughput screening system upgrades

- More samples / higher throughput

- Faster measurements 
- Increased reproducibility

o Develop an automated spray pyrolysis deposition system

o Develop a combinatorial slurry reactor for the production of hydrogen

- Combinatorial library synthesis and screening

0 Using new and existing high-throughput synthesis and screening technology, create and screen suitable new mixed oxide materials for electrochemical / photoelectrochemical hydrogen production.

o Improve and expand the chemical synthesis routes developed for automated high-throughput experimentation.

o Catalyze the surfaces and engineer the band-edges of the identified semiconductor materials as required.

o Synthesize, using conventional routes, selected materials identified in libraries for detailed structure-electronic analysis.

o Determine if existing photovoltaic (PV) device structures could be easily modified to effect the direct splitting of water.

\section{Accomplishments}

- Developed automated systems for material synthesis by electrochemical deposition (rapid-serial and parallel) and by spray pyrolysis.

- Developed automated systems for optical (UV-Vis spectroscopy), electrochemical, and photoelectrochemical (photocurrent, photovoltage, flat-band potential, action spectra, IPCE) characterization.

- Explored $\mathrm{WO}_{3}-\mathrm{MoO}_{3}$ mixed oxides / solid solutions, and found 50:50 W:Mo to be optimal for electrochromic and photoelectrochemical applications.

- Investigated mesostructured $\mathrm{ZnO}$ synthesized by block co-polymer templating, and improved upon hydrogen production by $30 \%$.

- Explored cobalt-doped $\mathrm{ZnO}$ solid solutions and found $4.4 \%$ cobalt to improve visible photocurrent ( $\mathrm{H}_{2}$ production) by a factor of 4 compared to pure $\mathrm{ZnO}$.

\section{Future Directions}

- Ternary and quaternary derivatives of $\mathrm{Zn}_{1-\mathrm{x}} \mathrm{Co}_{\mathrm{x}} \mathrm{O}$

o For improved corrosion resistance

o For improved catalytic redox activity

- Continue C-60 doping of oxide materials for visible light absorption.

- Transition metal doped $\mathrm{Fe}_{2} \mathrm{O}_{3}$.

- Single-sample slurry reactor for quantitative $\mathrm{H}_{2}$ analysis.

- Quantitative efficiencies for best materials found to date.

- Preliminary reactor concepts and economics for best materials.

\section{Introduction}

The overall project objective is to discover and optimize an efficient, practical, and economically sustainable material for photoelectrochemical production of bulk hydrogen from water - a clean, renewable route to hydrogen energy. The properties of the semiconductors investigated for this application, which are similar to those in photovoltaic devices, must satisfy conditions in several areas if cost-effective hydrogen production is to be realized: (1) efficient solar absorption, (2) effective charge separation 
/ transport, (3) appropriate conduction band / valence band energies relative to $\mathrm{H}_{2}$ and $\mathrm{O}_{2}$ redox potentials ("band matching"), (4) facile interfacial charge transfer, (5) long-term stability, and (6) low cost. A material which satisfies all the above conditions simultaneously could provide clean hydrogen in bulk and at low cost; unfortunately, no such material or system has been discovered or developed to date. The DOE has identified the following future targets for solar-to-hydrogen efficiency and durability: 2005, $7.5 \%$ and 1,000 hrs; 2010, $9 \%$ and 10,000 hrs; 2015, $14 \%$ and 20,000 hrs.

\section{Approach}

The approach of this project involves the application of combinatorial chemistry methods to discover and optimize photoelectrochemical materials and systems for cost-effective hydrogen production. This represents a shift in the research paradigm from conventional chemical research in that a combinatorial approach that features systematic and highspeed exploration of new metal-oxide based solid-state materials. By investigating large arrays of diverse materials, we are working to improve the understanding of the fundamental mechanisms and composition-structure-property relationships within these systems while discovering new and useful energy-producing photocatalysts. It should also be noted that our approach focuses upon the investigation of semiconductor materials that are inherently inexpensive, such as $\mathrm{ZnO}, \mathrm{WO}_{3}$, and $\mathrm{Cu}_{2} \mathrm{O}$. Although more expensive systems (eg. GaAs, InP, etc.) have generally demonstrated greater efficiency, cost and/or natural abundance could be problematic on a large scale, thus we are applying combinatorial techniques toward inexpensive host photocatalysts with the aim of improving their properties significantly while negligibly affecting cost.

\section{$\underline{\text { Results }}$}

We have designed and developed automated electrochemical synthesis and photoelectrochemical screening systems, Fig. 1 and 2, for a variety of new materials and we have focused primarily on $\mathrm{WO}_{3}$ and $\mathrm{ZnO}$ hosts, investigating libraries of variable composition and morphology. We have also developed a general method for the production of high surface area nanostructured films $\left(\mathrm{WO}_{3}, \mathrm{ZnO}, \mathrm{TiO}_{2}, \mathrm{Pt}\right)$ by utilizing electrochemically driven self-assembly of surfactants and a pulsed-electrodeposition scheme for depositing nanoparticulate pure metals (Pt, $\mathrm{Au}, \mathrm{Pd})$, alloys (Pt-Au, Pt-Ru) and metal oxides $\left(\mathrm{WO}_{3}\right)$ which we have incorporated into our automated synthesis and screening systems. By virtue of a mesostructured morphology (features $2-50 \mathrm{~nm}$ in size), transport distances for charge carriers (electrons and electron-vacancies) are decreased dramatically - thus recombination can be mitigated resulting in greater photoelectrochemical efficiency.

Mesostructured $\mathrm{ZnO}$ was synthesized by the addition of a block copolymer $\left(\mathrm{EO}_{20} \mathrm{PO}_{70} \mathrm{EO}_{20}\right)$ Structure Directing Agent (SDA) during electrochemical synthesis. A 56-member library explored a range of the SDA from 0 to $15 \mathrm{wt} .-\%$. TEM images, as shown in Fig. 3, reveal lamellar planes which were observed on all samples. Disordered mesopores were also observed (not shown). The high-throughput photoelectrochemical screening system was then used to characterize the samples. Fig. 3 illustrates the trend of zero-bias photocurrent for the samples as a function of the SDA concentration used during synthesis. Samples synthesized with low concentrations $(<1 \mathrm{wt} .-\%)$ of the SDA exhibited similar performance to the control $\mathrm{ZnO}$ sample, however samples synthesized 
with $2<$ [SDA] $<5$ wt.- $\%$ showed improved performance, with a maximum at 3 wt.- $\%$, where films demonstrated a $30 \%$ improvement over the control $\mathrm{ZnO}$. Films deposited with high concentrations of the SDA (>5\%) performed poorly with respect to the control samples, presumably because of poor wall crystallinity.

Several hundred samples of different $\mathrm{ZnO}$-based materials, exploring 24 different dopants, have been synthesized from a DMSO-based electrodeposition bath and screened photoelectrochemically with the aim of improving visible photon absorption and photoelectrohemical efficiency. We have shown significantly increased visible band absorption of $\mathrm{ZnO}$ through substitutional doping with $\mathrm{Co}$, and a 120-member library was synthesized to explore 27 Co dopant concentrations up to $7 \%$. X-Ray Photoelectron Spectroscopy (XPS) reveals that $\mathrm{Co}^{2+}$ is the predominant oxidation state of cobalt, and XRay Diffraction (XRD) confirms that the wurtzite structure (typical of pure $\mathrm{ZnO}$ ) is maintained. Figure 5 illustrates a decrease in bandgap with increasing cobalt content, as well as $\mathrm{Co}^{2+} d-d$ transitions in the $550-650 \mathrm{~nm}$ range, both of which represent increased visible photon absorption for cobalt-doped samples. Figure 6 exhibits results from photoelectrochemical screening. Under full illumination of the Xe lamp (which includes both UV and Vis radiation), photocurrent decreases as a function of increasing cobalt. When a UV cut-off filter is used to emulate the solar spectrum, however, a different trend emerges - photocurrent decreases with low cobalt concentrations $(<1 \%)$, but then climbs dramatically reaching a maximum at $4.4 \%$ cobalt, where photocurrent is four times that of pure $\mathrm{ZnO}$. After this point, photocurrent drops sharply, presumably due to increased defect-related recombination of charge carriers. Action spectra and IPCE were measured on select samples, revealing that the increased visible photon absorptions observed in Fig. 5 give rise to increased photoelectrochemical activity.

\section{Conclusions}

- The methodology of combinatorial material science has been applied to expedite the discovery of improved photocatalytic materials for hydrogen production.

- $\mathrm{WO}_{3}$ and $\mathrm{ZnO}$ host materials have been investigated extensively.

- Mesostructured $\mathrm{ZnO}$ demonstrated a $30 \%$ improvement in efficiency over a morphologically dense $\mathrm{ZnO}$.

- Cobalt-doped $\mathrm{ZnO}$ samples were explored in depth, with $\mathrm{Zn}_{0.956} \mathrm{Co}_{0.044} \mathrm{O}$ exhibiting optimal performance, an efficiency four times that of pure $\mathrm{ZnO}$. 


\section{New FY 2003 Publications/Presentations}

1. T.F. Jaramillo, S.-H. Baeck, A. Kleiman-Shwarsctein, K.-S. Choi, G.D. Stucky, and E.W. McFarland, "Automated electrochemical synthesis and photoelectrochemical characterization of $\mathrm{Zn}_{1-\mathrm{x}} \mathrm{Co}_{\mathrm{x}} \mathrm{O}$ thin films for solar hydrogen production," J. Comb. Chem. (accepted and in press, 2004).

2. T.F. Jaramillo, S.-H. Baeck, A. Kleiman-Shwarsctein, and E.W. McFarland, "Combinatorial electrochemical synthesis and screening of mesoporous $\mathrm{ZnO}$ for photocatalysis," Macromol. Rapid Comm., 2004, 25, 297.

3. S.-H. Baeck, T.F. Jaramillo, D.H. Jeong, E.W. McFarland, "Parallel synthesis and characterization of photoelectrochemically and electrochromically active tungsten molybdenum oxides", Chem. Comm., 2004, 4, 390.

4. S.-H. Baeck, T.F. Jaramillo, A. Kleiman-Shwarsctein, and E.W. McFarland, "Automated electrochemical synthesis and characterization of $\mathrm{TiO}_{2}$ supported $\mathrm{Au}$ nanoparticle electrocatalysts", Meas. Sci. Tech., submitted (May 2004).

5. T.F. Jaramillo, S.-H. Baeck, A. Kleiman, K.-S. Choi, G.D. Stucky, E.W. McFarland, "Automated electrochemical synthesis and photoelectrochemical characterization of $\mathrm{Zn}_{1-\mathrm{x}} \mathrm{Co}_{\mathrm{x}} \mathrm{O}$ thin films for solar hydrogen production" in preparation (June 2004).

6. E. McFarland,"Fundamentals of electrocatalysis and photoelectrocatalysis in hydrogen production" and "Combinatorial methods for discovery and optimization of catalysts for hydrogen production", Presented at the International Summer School "Towards a Hydrogen-based Society", Lyngby, Denmark August 2003.

7. E. McFarland, "High-Throughput Discovery of New and Optimized Metal Oxide Photocatalysts”, Invited talk, Gordon Research Conference on Future Directions in Combinatorial Materials Science, January 2003.

8. E. McFarland, "Combinatorial Electrochemistry for the Discovery of New and Improved Mixed Metal Oxide Photoelectrocatalysts”, Invited talk, General Electric, Corporate R+D Center, September 2003.

9. A. Kleiman-Shwarsctein, "Automated spray pyrolysis system for hematite synthesis as a photocatalyst for hydrogen production", Poster, Presented at $227^{\text {th }}$ American Chemical Society (ACS) National Meeting, Anaheim, California, March 2004.

10. T.F. Jaramillo, "Optimized Materials for Photoelectrochemical Hydrogen Production", Thesis defense, Dept. Chemical Engineering, University of California, Santa Barbara, June 2004. 


\section{Acronyms}

DMSO - Dimethyl Sulfoxide

IPCE - Incident Photon Conversion to Electrons

SDA - Structure Directing Agent

TEM - Transmission Electron Microscopy

XPS - X-Ray Photoelectron Spectroscopy

XRD - X-Ray Diffraction

\section{Figure Captions}

Figure 1. Automated electrochemical synthesis based on rapid-serial deposition. 120

independent electrochemical cells are sealed upon a single $14 \mathrm{~cm} \times 16 \mathrm{~cm}$ conductive substrate. Figure 2. Automated photoelectrochemical screening. A unique photoelectrochemical probe is stepped across the library, analyzing one sample at a time in automated fashion, measuring photocurrent, photovoltage, cyclic voltammograms, action spectra, etc.

Figure 3. TEM image of mesostructured $\mathrm{ZnO}$ and results of zero-bias photocurrent screening. 3 wt. $-\%$ of the SDA gave rise to a $30 \%$ improvement in photocurrent.

Figure 4. XPS (top) and XRD (bottom) of $\mathrm{Zn}_{1-\mathrm{x}} \mathrm{Co}_{\mathrm{x}} \mathrm{O}$ library samples. XPS reveals $\mathrm{Co}^{2+}$ as the predominant oxidation state, XRD shows the wurtzite structure is maintained regardless of composition.

Figure 5. UV-Vis spectroscopy of $\mathrm{Zn}_{1-\mathrm{x}} \mathrm{Co}_{\mathrm{x}} \mathrm{O}$ library samples. Bandgap decreases with increasing cobalt, and characteristic $\mathrm{Co}^{2+} d-d$ transitions are observed. Clearly, cobalt doping of $\mathrm{ZnO}$ gives rise to increased visible photon absorption.

Figure 6. Zero-bias photocurrent screening (top) and IPCE (bottom) of $\mathrm{Zn}_{1-\mathrm{x}} \mathrm{Co}_{\mathrm{x}} \mathrm{O}$ library samples. Under solar-spectrum emulated irradiation, the photocurrent of $Z_{0.956} \mathrm{Co}_{0.044} \mathrm{O}$ was 4 times that of pure $\mathrm{ZnO}$. IPCE shows that the increased visible absorptions observed in Fig. 5 are responsible for the increased photoelectrochemical activity. 


\section{$\underline{\text { Figures }}$}

Figure 1.

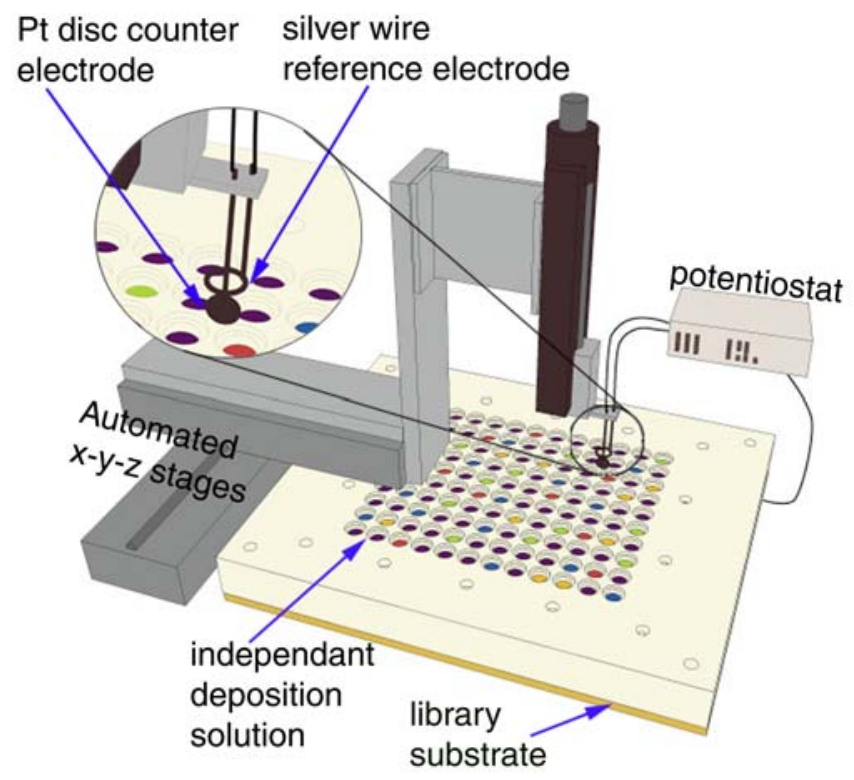

Figure 2.

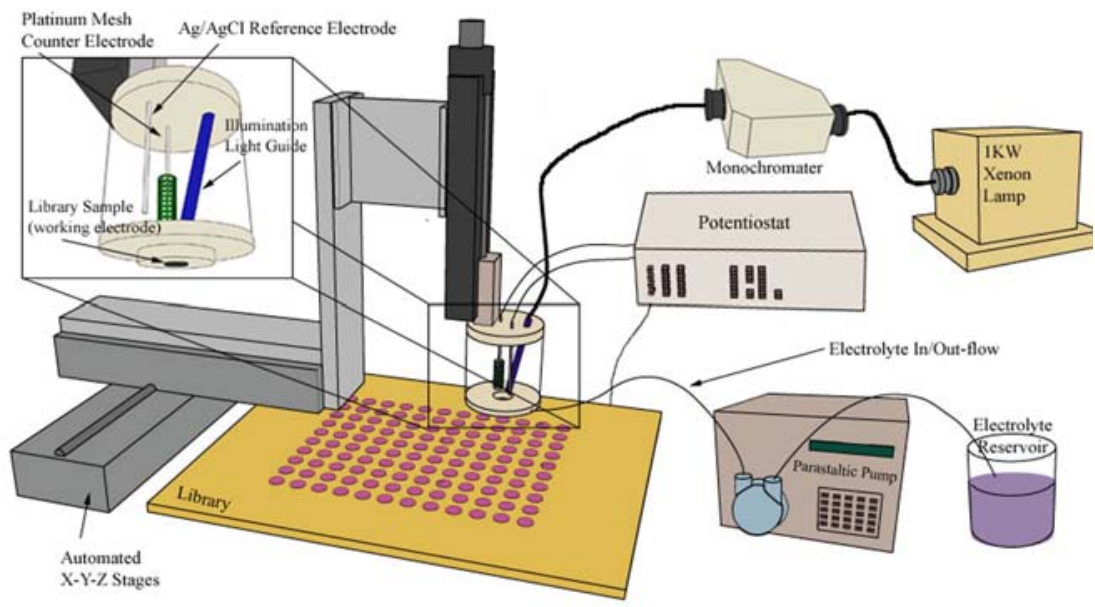


Figure 3.
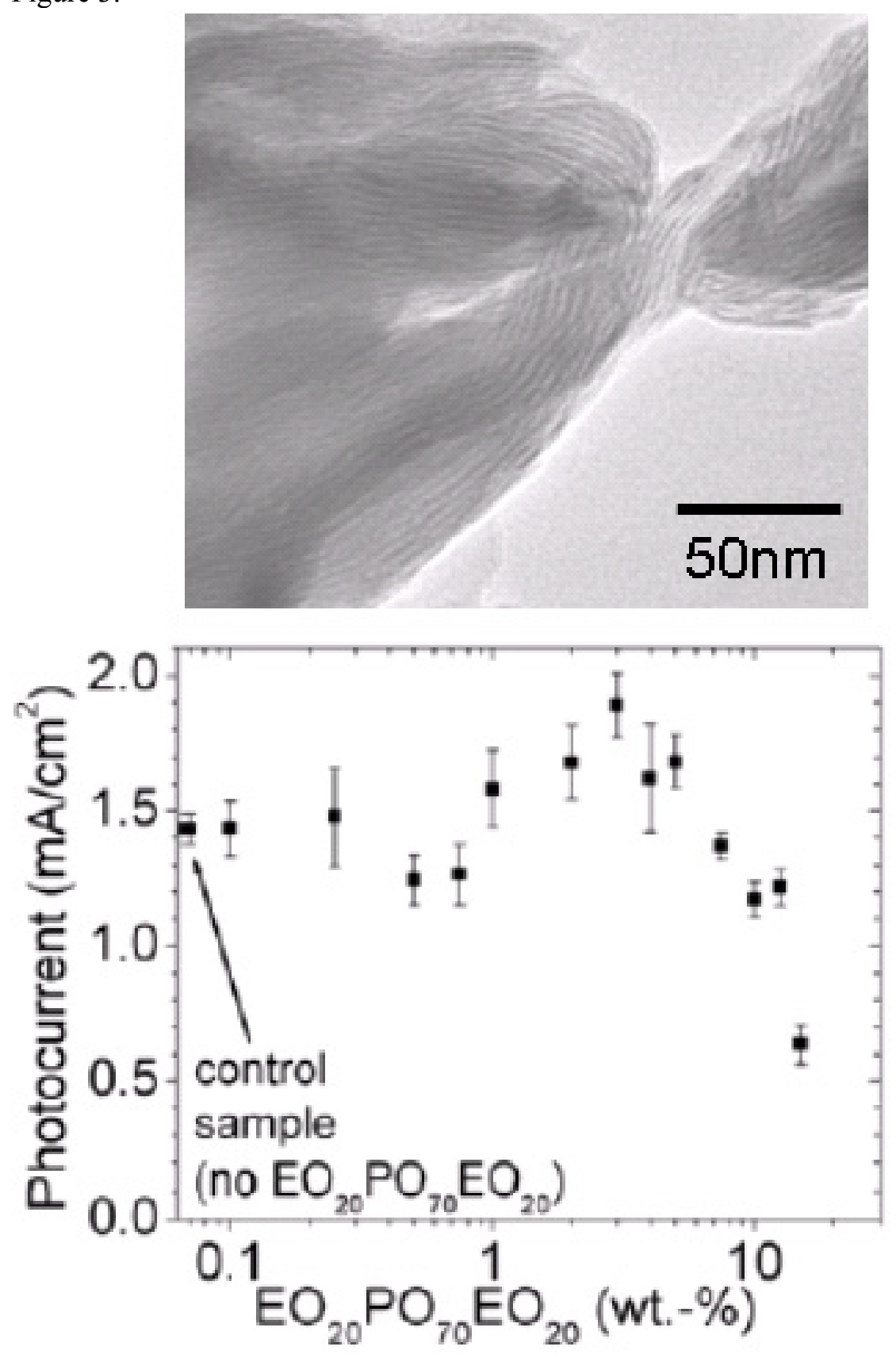
Figure 4.
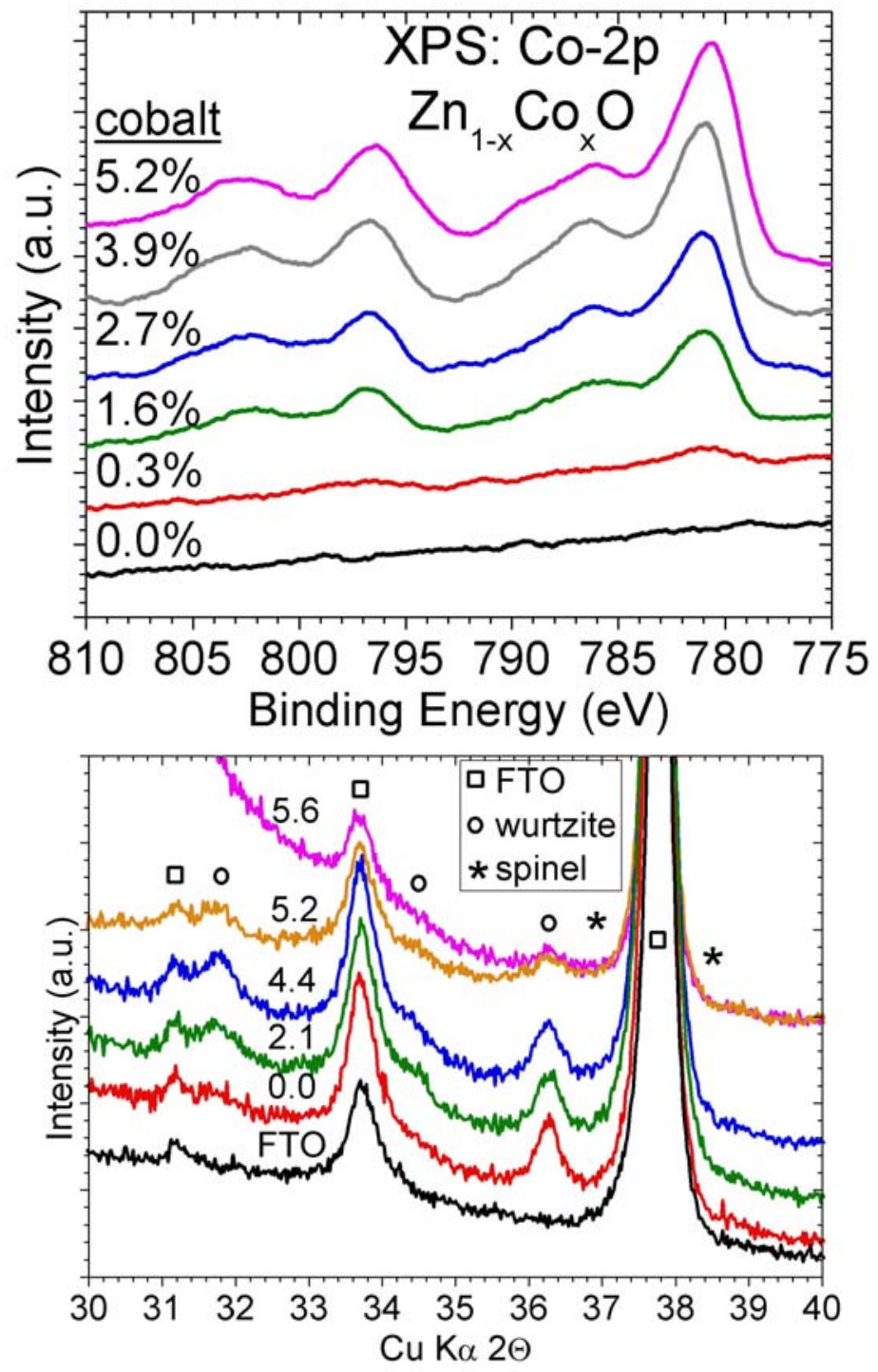
Figure 5.

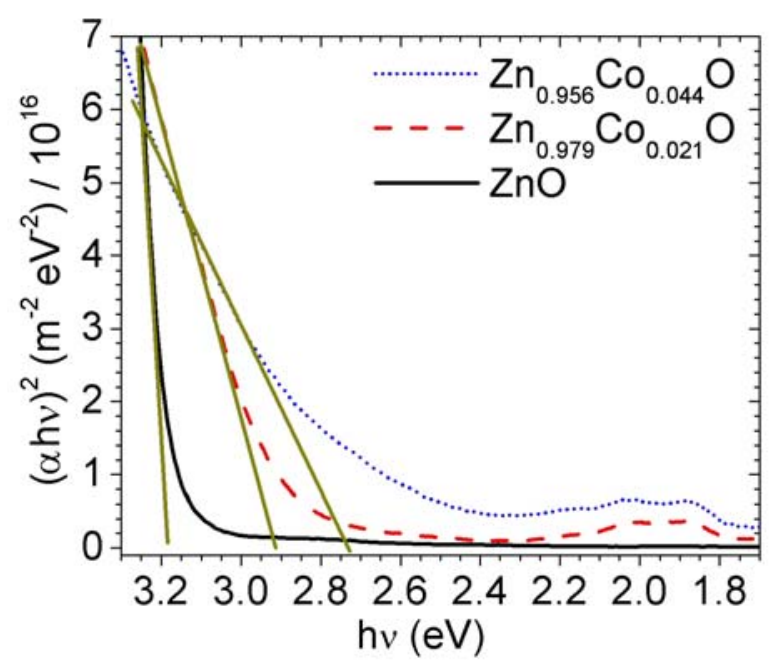

Figure 6.
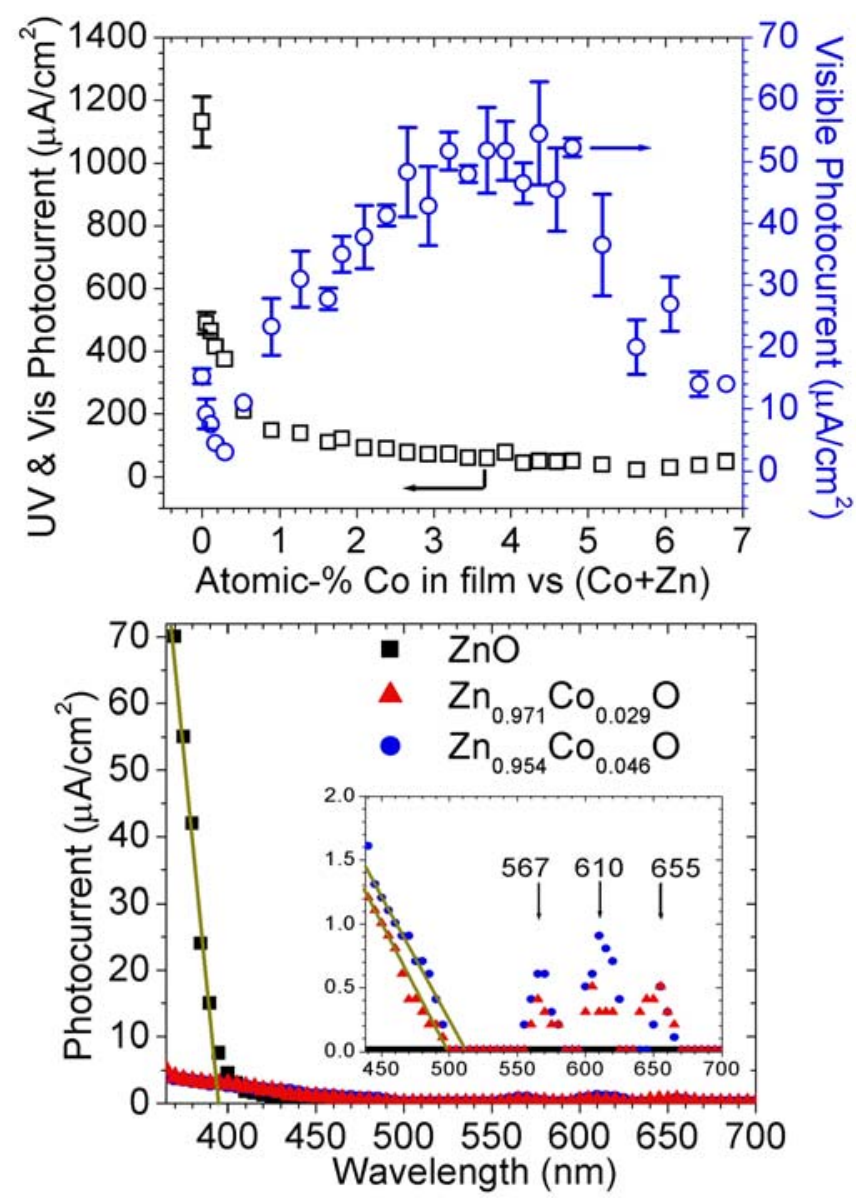